research

\title{
High-fat diet aggravates glucose homeostasis disorder caused by chronic exposure to bisphenol A
}

\author{
Shibin Ding ${ }^{1,2}$, Ying Fan', Nana Zhao ${ }^{3}$, Huiqin Yang', Xiaolei $\mathrm{Ye}^{3}$, Dongliang $\mathrm{He}^{1}$, \\ Xin Jin', Jian Liu', Chong Tian', Hongyu Li', Shunqing $X^{1} \mathbf{u}^{2}$ and Chenjiang Ying ${ }^{1,2}$ \\ ${ }^{1}$ Department of Nutrition and Food Hygiene and ${ }^{2} \mathrm{MOE}$ Key Lab of Environment and Health, \\ School of Public Health, Tongji Medical College, Huazhong University of Science and Technology, \\ 13 Hangkong Road, Wuhan 430030, People's Republic of China \\ ${ }^{3}$ School of Environmental Science and Public Health, Wenzhou Medical College, Wenzhou 325000, China
}

\author{
Correspondence \\ should be addressed \\ to $C$ Ying \\ Email \\ yingcj@hust.edu.cn
}

\begin{abstract}
Epidemiological findings on the association between bisphenol A (BPA, 2,2-bis-(4-hydroxyphenyl)propane) exposure and type 2 diabetes mellitus (T2DM) are paradoxical. In animal studies, BPA has been shown to disrupt pancreatic function and blood glucose homeostasis even at a reference 'safe' level during perinatal period. In this study, we explored the effects of long-term paternal exposure to a 'safe' level of BPA on parents themselves and their offspring. Adult male genitor rats fed with either standard chow diet (STD) or high-fat diet (HFD) were treated respectively with either vehicle or BPA ( $50 \mu \mathrm{g} / \mathrm{kg}$ per day) for 35 weeks. The male rats treated with vehicle or BPA for 21 weeks were then used as sires, and the adult female rats were fed with STD during the gestation and lactation. Offspring rats were weaned on postnatal day 21 and fed with STD in later life. Metabolic parameters were recorded on the adult male rats and their adult offspring. BPA exposure disrupted glucose homeostasis and pancreatic function, and HFD aggravated these adverse effects. However, BPA exposure did not alter body weight, body fat percentage, or serum lipid. In addition, the paternal BPA exposure did not cause adverse reproductive consequence or metabolic disorder in the adult offspring. Our findings indicate that chronic exposure to a predicted 'safe' dose of BPA contributes to glucose metabolic disorders, and that HFD aggravates these adverse effects in paternal rats.
\end{abstract}

Key Words

- bisphenol A

- endocrine disruptor

- glucose homeostasis

- high-fat diet

- autophagy

\section{Introduction}

The prevalence of type 2 diabetes mellitus (T2DM) is increasing worldwide, which makes this metabolic disease a severe threat to health (Guariguata et al. 2011). Accumulating evidence indicates that bisphenol A (BPA, 2,2-bis-(4-hydroxyphenyl)propane) exposure is involved in T2DM of humans. BPA, an environmental endocrine disruptor, is ubiquitous in human lives and is used for making a variety of common consumer goods and for industrial purposes. Thus, people over the world are frequently exposed to low levels of BPA primarily derived from food and beverage containers (Vandenberg et al. 2007). Epidemiological studies on the association between BPA levels and T2DM are inconsistent. Data obtained from adults in the US National Health and Nutritional Examination Survey have indicated that higher urinary BPA concentrations are associated with 
T2DM (Lang et al. 2008), and the association has been found to be consistent in normal-weight subjects as well as overweight/obese subjects (Shankar \& Teppala 2011). In addition, a positive association of BPA levels with obesity and insulin resistance in middle-aged and elderly Chinese adults has been reported by Wang et al. (2012). Increasing urinary BPA levels have been reported to be positively associated with pre-diabetes among adults in the USA (Sabanayagam et al. 2013), as well as with insulin resistance and hyperinsulinemia among adults in the USA (Beydoun et al. 2013). In contrast, population-based studies in adults from the USA, China, and Korea have not found any significant association between higher urinary BPA concentrations and T2DM (Melzer et al. 2010, Ning et al. 2011, Kim \& Park 2013).

The U.S. Environmental Protection Agency (EPA) and the European Food Safety Agency have established that a dose of $<50 \mu \mathrm{g} / \mathrm{kg}$ per day (tolerable daily intake) is 'safe' (Vandenberg et al. 2007). The predicted 'safe' dose of BPA is calculated by dividing the lowest observed adverse effect level $(50 \mathrm{mg} / \mathrm{kg}$ per day) by three safety factors (human variability, interspecies differences, and variability in toxicokinetics and toxicodynamics, tenfold for each factor). However, treatment with BPA $(10-50 \mu \mathrm{g} / \mathrm{kg}$ per day) has been found to increase insulin secretion and cause hyperinsulinemia in Swiss albino OF1 male mice (8-10 weeks old) (Alonso-Magdalena et al. 2006, 2008). Moreover, glucokinase has been demonstrated to be the body's glucose sensor in the liver, and acute and shortterm ( 2 weeks) exposures to the predicted 'safe' dose of BPA have been found to decrease hepatic glucokinase activity and function in 6-month-old C57BL/6 male mice (Perreault et al. 2013). Marmugi et al. (2012) reported that the exposure of 6-week-old male CD1 mice to different doses of BPA $(5,50,500$, and $5000 \mu \mathrm{g} / \mathrm{kg}$ per day) for 28 days may affect de novo fatty acid synthesis, which has been established through increase in the expression of lipogenic genes. These results indicate that the predicted 'safe' dose may not be really safe. In recent years, life styles dominated by an increase in the consumption of highfat diets have contributed to the accelerated diabetes epidemic (Hu 2011), and consumption of fat-rich products favors co-exposure to BPA and HFD. Therefore, it is necessary to study whether HFD will aggravate the adverse effects of exposure to a 'safe' dose of BPA. Perinatal exposure to the predicted 'safe' dose of BPA has been found to disrupt glucose homeostasis in adult offspring (Alonso-Magdalena et al. 2010, Wei et al. 2011). However, whether paternal BPA treatment will induce metabolic sequelae in offspring is not clear.
Recently, many studies have demonstrated that increased endoplasmic reticulum (ER) stress and abnormal autophagy induce pancreatic $\beta$-cell dysfunction and diabetes (Jung et al. 2008, Quan et al. 2012, Boslem et al. 2013, Miani et al. 2013). The ER is well developed in pancreatic $\beta$-cells in which insulin is synthesized. Mammalian Bip (Grp78) is an abundant chaperone in ER, and it is involved in ER-associated degradation of misfolded proteins (Lee et al. 2003, Bukau et al. 2006). Before the development of diabetes, more insulin is produced to compensate for $\beta$-cell dysfunction. When the capacity to synthesize insulin is overloaded in the ER of $\beta$-cells, the misfolded proinsulin protein gets accumulated and induces ER stress. In the face of ER stress and accumulated misfolded proprotein, Bip expression levels in cells are rapidly upregulated (Lee et al. 2003) and autophagy is also increased (Bachar-Wikstrom et al. 2013). Autophagy, a vital catabolic process, is involved in the degradation of unnecessary cellular components and recycling of cellular components, as well as in the relocation of nutrients for principal processes for survival (Kuma et al. 2004, Levine \& Klionsky 2004). The adverse effects of BPA on glucose homeostasis are probably related to early dysfunction of insulin synthesis, especially involving ER stress, misfolded protein, and autophagy. Further studies are needed to delineate the effect of the 'safe' dose of BPA on autophagy of pancreas and pancreatic $\beta$-cells.

The primary aim of this study was to demonstrate whether long-term paternal exposure to 'safe' levels of BPA would disrupt pancreatic function and blood glucose homeostasis in parents themselves and their offspring, as well as whether HFD would aggravate the adverse effects of BPA exposure. The secondary aim was to investigate the role of ER stress and autophagy in pancreas and $\beta$-cells treated with BPA.

\section{Materials and methods}

\section{Chemicals and reagents}

BPA, (CAS no. 80-05-7, $\left(\mathrm{CH}_{3}\right)_{2} \mathrm{C}\left(\mathrm{C}_{6} \mathrm{H}_{4} \mathrm{OH}\right)_{2}, \geq 99 \%$ purity) was obtained from Sigma Chemical Company. Assay kits for serum glucose, serum total cholesterol (TC), and triglycerides (TGs) were purchased from BIOSINO Biotechnology and Science, Inc. (Beijing, China). Serum insulin was obtained from Bai Wo (Shanghai, China). TRIzol was from Invitrogen, Inc. and the real-time quantitative PCR Kit was purchased from TAKARA Bio, Inc. (Otsu, Shiga, Japan). LC3B antibody was purchased from Cell Signaling Technology (Billerica, MA, USA),

Published by Bioscientifica Ltd. 
insulin antibody was obtained from Merck Millipore (Billerica, MA, USA), and secondary antibody and FITCconjugated secondary antibody were obtained from Abcam (Cambridge, UK). All other chemicals were of the highest grade commercially available.

\section{Maintenance of animals}

The study was approved by the Animal Care and Ethical Use Committee of Tongji Medical College, in accordance with the guidelines for care and use animals published by Tongji Medical College, Huazhong University of Science and Technology.

Male (150-180 g) Wistar rats were supplied by the Hubei Research Center of Laboratory Animals (China). The animals were provided with standard rodent chow and tap water and allowed to eat and drink ad libitum and were housed at $21 \pm 1{ }^{\circ} \mathrm{C}, 60 \pm 10 \%$-relative humidity, and $12 \mathrm{~h}$ light: $12 \mathrm{~h}$ darkness cycle. The animals were kept in polypropylene cages, and glass water bottles were used to eliminate potential contamination with BPA.

\section{Experimental design}

Male genitor rats were randomly divided into four groups with ten rats in each group. The animals were treated as follows: i) the standard chow diet (STD) group was fed with STD; ii) the STD-BPA group was fed with STD and treated with BPA; iii) the HFD group received HFD; and iv) the HFD-BPA group was fed with HFD and treated with BPA. The daily dose of BPA used for treatment was $50 \mu \mathrm{g} / \mathrm{kg}$ body weight per day and all the male genitors (paternal rats) were treated for 35 weeks consecutively. The details of BPA $(50 \mu \mathrm{g} / \mathrm{kg}$ per day) treatment methods have been described previously (Fan et al. 2013): BPA was dissolved in corn oil and diluted with three stock solutions $(20,40$, and $60 \mu \mathrm{g} / \mathrm{ml}$ ). The necessary volumes of stock solution were calculated based on the daily body weight and the suitable stock solution was selected to limit the volume of stock solution $<0.5 \mathrm{ml}$. Corn oil was added to this solution to form a total volume of $0.5 \mathrm{ml}$, this was then directly mixed with standard rodent chow ( $5 \mathrm{~g} / \mathrm{rat})$ as the test diet. In the morning, the male genitor rats were provided with test diet or rodent chow diet containing the same volume of corn oil $(0.5 \mathrm{ml})$ as that of test diet $(5 \mathrm{~g} / \mathrm{rat})$, and sufficient chow diet or HFD was provided if the test diet was completely consumed. The composition of the HFD was as follows $(\mathrm{w} / \mathrm{w})$ : standard chow, 60\%; custard powder, $8 \%$; lard, $12 \%$; sugar, $12 \%$; peanut power, $6 \%$; and milk,
Table 1 The percentage composition of the main components in the standard diet (STD) and the high-fat diet (HFD)

\begin{tabular}{|c|c|c|c|c|}
\hline Diets & $\begin{array}{l}\text { Fat } \\
(\%)\end{array}$ & $\begin{array}{c}\text { Carbohydrate } \\
(\%)\end{array}$ & $\begin{array}{c}\text { Protein } \\
(\%)\end{array}$ & $\begin{array}{c}\text { Total energy } \\
(\mathrm{KJ} / \mathrm{g})\end{array}$ \\
\hline STD & 13.68 & 64.44 & 21.88 & 13.77 \\
\hline HFD & 41.26 & 39.61 & 19.13 & 19.21 \\
\hline
\end{tabular}

1\% (Tian et al. 2013). The energy supply of two diets is listed in Table 1.

After 21 weeks of treatment, genitor male rats were mated with genitor female $(260-300 \mathrm{~g})$ rats that were obtained from the Hubei Research Center of Laboratory Animal (China). The genitor female rats were fed with STD throughout the experiments. The consumption of different diets was calculated daily and body weight was monitored weekly (from exposure 0 to 35 weeks). The day of birth was designated as postnatal day (PND) 1. The dams were weighed on PND 1, 5, 10, 15, and 21 and the sex ratio and litter size were calculated on PND 1 . The pups were weaned on PND 21 and then fed with STD until they were killed at the age of 10 weeks; after weaning the male and female offspring were housed separately by paternal grouping. Each group of offspring contained ten pups from three litters. After 35 weeks of treatment, all the genitor animals were killed by decapitation. Pancreas, subcutaneous fat pad, and other tissues were collected and weighed, then immediately frozen in liquid nitrogen and stored at $-80^{\circ} \mathrm{C}$ for future experiments.

\section{Energy intake assessment}

The total consumption of the combination diets during 35 weeks was calculated according to daily food consumption. The total energy intake per cage (two rats) was calculated as follows: the total consumption of diet for 35 weeks multiplied by the percentages of fat, protein, and carbohydrate in the two diets, and further multiplied by the corresponding caloric values of fat, protein, and carbohydrate respectively.

\section{Determination of serum and hepatic lipid parameters}

Blood was collected from the tail vein of $12 \mathrm{~h}$ fasted rats. Serum was separated from whole blood by centrifugation. The levels of fasting serum glucose were measured by glucose oxidase-peroxidase assays (BIOSINO Biotechnology and Science, Inc.). The levels of serum TG and TC were assayed using enzymatic colorimetric assays (BIOSINO Biotechnology and Science, Inc.) following the

Published by Bioscientifica Ltd. 
manufacturer's instructions. Hepatic lipids were extracted by the procedure developed by Loison et al. (2002), and the extracted lipid was used to determine the TG and TC levels using enzymatic kits. Serum insulin was measured using ELISA Kit (Bai Wo). All serum parameters were determined spectrophotometrically using a SpectraMax M2 microplate reader (Molecular Devices, Sunnyvale, CA, USA).

\section{Insulin resistance index and insulin sensitivity index}

Homeostasis index model assessment for insulin resistance index (HOMA-IR) and insulin sensitivity index (ISI) were analyzed. The HOMA-IR was calculated as follows: (fasting serum insulin concentration) $\times$ (fasting serum glucose concentration)/22.5 (Matthews et al. 1985, Simental-Mendia et al. 2012), and the ISI was calculated using the following equation: $1 / \ln$ (fasting serum insulin concentration $\times$ fasting serum glucose concentration) (Wang et al. 2013).

\section{Glucose tolerance tests}

For the intraperitoneal glucose tolerance test (IPGTT), paternal rats treated for 30 weeks were fasted for $15 \mathrm{~h}$ and glucose $(2.0 \mathrm{~g} / \mathrm{kg}$ body weight) was injected intraperitoneally. Blood samples were collected from the tail vein and a drop of blood was directly put onto the indicator paper. The result was soon displayed on the meter window as millimole per liter. Blood glucose level was determined at the indicated time points $(0,15,30,60$, and $120 \mathrm{~min})$ with a commercial hand-held glucometer (ACCU-CHEK Active; Roche) (Marmugi et al. 2012). In addition, an index of glucose tolerance was calculated using the area under the curve (AUC).

\section{Pancreatic $\beta$-cell mass}

The whole pancreas of each of the paternal rats was collected and weighted after they were killed. For immunofluorescence, the pancreas were fixed in $4 \%$ paraformaldehyde and then embedded in paraffin. An immunofluorescent staining of the series of tissue sections (5 $\mu \mathrm{m}$ thick) was prepared with anti-insulin (diluted 1:100, Merck Millipore) and FITC-conjugated secondary antibody (Abcam) for determining $\beta$-cell mass. The sections were photographed under a microscope (BX61, Olympus America) using Image Pro Plus version 6.0 Software (Media Cybernetics, Silver Spring, MD, USA). Pancreatic $\beta$-cell areas were calculated using the image acquired from insulin-stained cells in the sections. The $\beta$-cell masses were calculated by multiplying the percentage of the area of insulin-positive cells in the total area of pancreatic tissue by the pancreas weight as described previously (Garofano et al. 1998, Fu et al. 2012).

\section{Quantitative real-time PCR}

Total RNA was extracted from isolated paternal rats' islets using TRIzol, following the manufacturer's instructions, and then quantified by u.v., spectrophotometry. For all the samples, $1 \mu \mathrm{g}$ total RNA and random primers were used to perform the RT reaction. Real-time PCR was carried out using the SYBR Green detection system on an ABI PRISM 7900 machine (Applied Biosystems) with the following conditions: one cycle, $95^{\circ} \mathrm{C}, 5 \mathrm{~s} ; 40$ cycles, $95^{\circ} \mathrm{C}, 10 \mathrm{~s}$; and
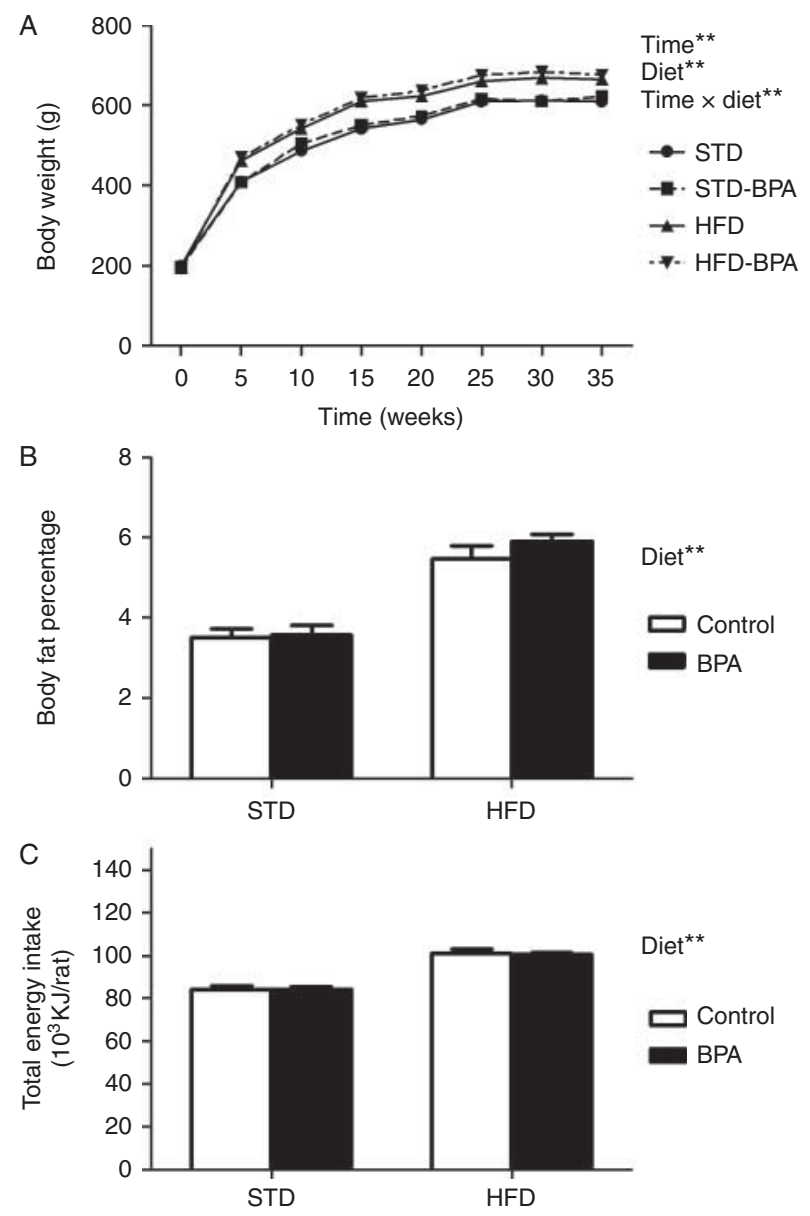

Figure 1

Effects of BPA on body weight and energy intake in paternal rats. (A) Body weight $(n=10)$. (B) Body fat percentage $(n=8-10)$. (C) Total energy intake $(n=5) .{ }^{*} P<0.01$. Data are expressed as mean \pm s.E.M. Time** indicates exposure duration. Diet** indicates the variety of diet. Time $\times$ diet $^{* *}$ indicates the interaction effect between exposure duration and variety of diet.

Published by Bioscientifica Ltd. 
$57^{\circ} \mathrm{C}, 30 \mathrm{~s}$. The $2^{-\triangle \Delta C \mathrm{~T}}$ method was adopted for the data analysis of relative gene expression, and $\beta$-actin was used as an endogenous reference gene. Primers for genes of interest used in the real-time PCR were as follows: $\beta$-actin (NM031144) sense, CGT GCG TGA CAT TAA AGA G and anti-sense, TTG CCG ATA GTG ATG ACC T; Lc3 (Map1lc3b) (NM022867) sense, ATA GAG CGA TAC AAG GGT G and anti-sense, AGG AAG AAG GCT TGG TTA; Beclin1 (NM053739) sense, CGT GGA GAA AGG CAA GAT and anti-sense, AGG ACA CCC AAG CAA GAC; and Bip (Hspa5) (NM013083) sense, ATA ATC AGC CCA CCG TAA CAA and anti-sense, GCA GGA GGG ATT CCA GTC AG.

\section{Immunohistochemistry and confocal microscopy for pancreas in paternal rats}

The pancreas tissues were fixed in $4 \%$ paraformaldehyde, dehydrated, and embedded in paraffin according to the standard methods for immunohistochemistry. Sections ( $5 \mu \mathrm{m}$ thick) were cut and the paraffin was removed by serial standardized steps. The sections were incubated overnight at $4{ }^{\circ} \mathrm{C}$ with the primary antibody: rabbit antiLC3B (diluted 1:100, Cell Signaling Technology), and then the sections were incubated for $1 \mathrm{~h}$ with the appropriate secondary antibody. An Olympus BX6 microscope and Image Pro Plus version 6.0 Software (Media Cybernetics) were used to performed the analysis. For immunofluorescence and confocal microscopy, incubation was performed with anti-insulin (diluted 1:100, Merck Millipore) combined with rat anti-LC3B antibody (diluted 1:100, Cell Signaling Technology) overnight at $4{ }^{\circ} \mathrm{C}$. To achieve insulin and LC3 double-labeling, the sections were incubated with the following mixtures of secondary antibodies including rabbit anti-mouse-FITC and goat anti-rabbit-cy3 for $1 \mathrm{~h}$. The sections were washed three times with PBS before each step of incubation with antibody. Confocal microscopy (UltraView VOX, PerkinElmer, USA) was used to examine the colocalization between LC3 and $\beta$-cell.

\section{Protein extraction and western blot analysis}

Protein expression of LC3 in the pancreas was measured with western blot analysis. Pancreas tissues were homogenized and then lysed in extraction buffer containing $50 \mathrm{mmol} / \mathrm{l}$ Tris- $\mathrm{HCl}(\mathrm{pH} 8.0), 150 \mathrm{mmol} / \mathrm{l} \mathrm{NaCl}$, $1 \%$ Nonidet-P40, $1 \%$ sodium deoxycholate, $0.1 \%$ SDS, $0.1 \mathrm{mmol} / 1$ dithiothreitol, $0.05 \mathrm{mmol} / 1$ phenylmethylsulphonyl fluoride, $0.002 \mathrm{mg} / \mathrm{ml}$ aprotinin, $0.002 \mathrm{mg} / \mathrm{ml}$ leupeptin, and $1 \mathrm{mmol} / \mathrm{l} \mathrm{NaVO}_{3}$ (Ying et al. 2003). The concentration of protein was determined using Bio-Rad DC Protein Assay Reagent (Bio-Rad). Proteins (a total of $100 \mu \mathrm{g} /$ lane) were electrophoretically resolved on $15 \%$ SDS-PAGE and transferred onto the PVDF membranes $(0.22 \mu \mathrm{m}$, Bio-Rad) according to the method of Amersham Biosciences. $\beta$-Actin (1:10 000, Sigma-Aldrich Chemical Company) expression was used as a loading control. The membranes were incubated with anti-LC3B antibody (diluted 1:1000, Cell Signaling Technology) overnight at $4{ }^{\circ} \mathrm{C}$ and washed three times in washing buffer (Tris-buffered saline and $0.05 \%$ Tween-20) for $10 \mathrm{~min}$ each time, and then incubated with the respective HRP-conjugated secondary antibodies (1:5000; Beyotime, Haimen, Jiangsu, China) for $1 \mathrm{~h}$ at room temperature. After the membranes were washed three times again,
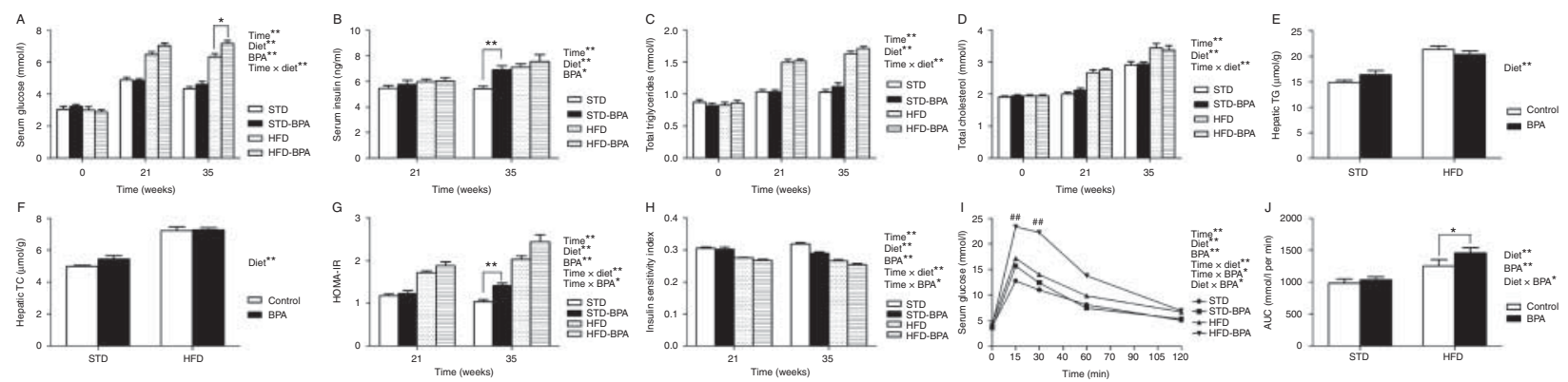

Figure 2

Serum metabolite and glucose tolerance test (GTT) in paternal rats. (A) Blood glucose. (B) Serum insulin. (C) Total triglycerides (TGs). (D) Total cholesterol (TC). (E) Hepatic total TGs. (F) Hepatic TC $(n=8-10)$. (G) HOMAIR $(n=10)$. (H) Insulin sensitivity index (ISI; $n=10)$. (I) Blood glucose during GTT after 30-week BPA treatment $(n=7)$. (J) AUC of IPGTT $(n=7)$. ${ }^{\# \# ~} P<0.01$ for the HFD-BPA group compared with the HFD group. The inset in (J) represents the mean total glucose AUC. ${ }^{\star} P<0.05$ and ${ }^{\star} * P<0.01$.
Data are expressed as mean \pm S.E.M. Time** indicates exposure duration. Diet** indicates the variety of diet. BPA* or BPA** indicate BPA treatment. Time $\times$ diet** indicates interaction effect between exposure duration and variety of diet. Time $\times B P A * *$ indicates interaction effect between exposure duration and BPA treatment. Diet $\times B P A *$ indicates interaction effect of variety of diet and BPA treatment. http://joe.endocrinology-journals.org DOI: 10.1530/JOE-13-0386
() 2014 Society for Endocrinology Printed in Great Britain
Published by Bioscientifica Ltd. 

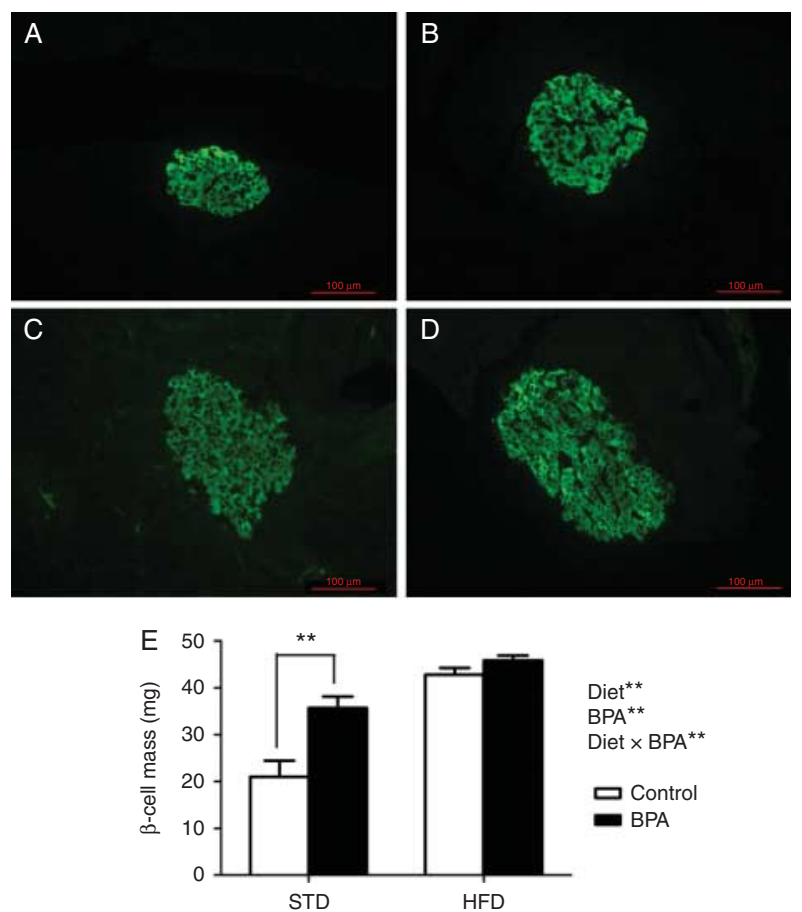

Figure 3

Pancreatic $\beta$-cell mass in paternal rats ( $n=3$ per group). (A) STD,

(B) STD-BPA, (C) HFD, and (D) HFD-BPA ( $20 \times$ magnification, bars $=100 \mu \mathrm{m})$ indicated by immunofluorescence staining for insulin in pancreatic sections of rats; $(E) \beta$-cell mass of rats of the four groups. Data are shown as means \pm S.E.M. ${ }^{* *} P<0.01$; diet** indicates the variety of diet; BPA** indicates BPA treatment; and diet $\times B P A * *$ indicates interaction effect of variety of diet and BPA treatment.

protein expression was visualized with an ECL detection system (Syngen, Cambridge, UK) and analyzed by software Chemidoc-Quantity-One (Bio-Rad Laboratories).

\section{Statistical analysis}

All data were analyzed with SPSS13.0 (SPSS). The results are expressed as mean \pm s.E.M. Repeated measures ANOVA, with BPA and diet (STD or HFD) as repeated measures, was used for the body weight, serum glucose, insulin, total TGs, TC, HOMA-IR, and ISI. The Greenhouse-Geisser test was used to revise degree of freedom when Mauchly's test of sphericity showed $P<0.05$. Bonferroni's post hoc test was used as multiple comparisons when appropriate. A $2 \times 2$ factorial ANOVA was used to determine the main effects of BPA and diet and to consider the potential interactions with BPA and diet for body fat percentage, energy intake, hepatic TG, TC, AUC, $\beta$-cell mass, LC3-positive area, LC3 protein expression, litter size, birth weight, and sex ratio. The mRNA expressions of $L c 3$, Beclin1, and Bip, as well as serum glucose at different time points in the IPGTT were analyzed for statistical significance by the non-repeated ANOVA, followed by post hoc analysis (Bonferroni's test). Statistical differences between two groups were calculated by the unpaired Student's t test. All $P$ values were two-tailed and $P$ values $<0.05$ were considered significant.

\section{Results}

\section{Body weight and energy intake of paternal rats}

The body weight, body fat percentage, and total energy intake of HFD fed animals were significantly higher than those of STD-fed animals $(P<0.01)$. While there was no significant difference in body weight (Fig. 1A), body fat percentage (Fig. 1B), or total energy intake (Fig. 1C) between the STD group and the STD-BPA group, or between the HFD group and the HFD-BPA group. These results indicated that BPA has no direct effect on total body weight, body fat percentage, or energy intake.

\section{Serum metabolite and hepatic lipid levels in paternal rats}

The serum metabolite levels in paternal rats were measured before exposure, after 21 weeks, and after 35 weeks of BPA exposure respectively. The level of serum glucose was significantly increased in BPA-treated groups compared with untreated groups $(P<0.01)$. Higher serum glucose level were observed in the HFD-BPA group compared with the HFD group after 35-week treatment with BPA $(P<0.05)$, whereas BPA did not result in a statistically significant difference in STD-fed rats (Fig. 2A). In addition, the serum

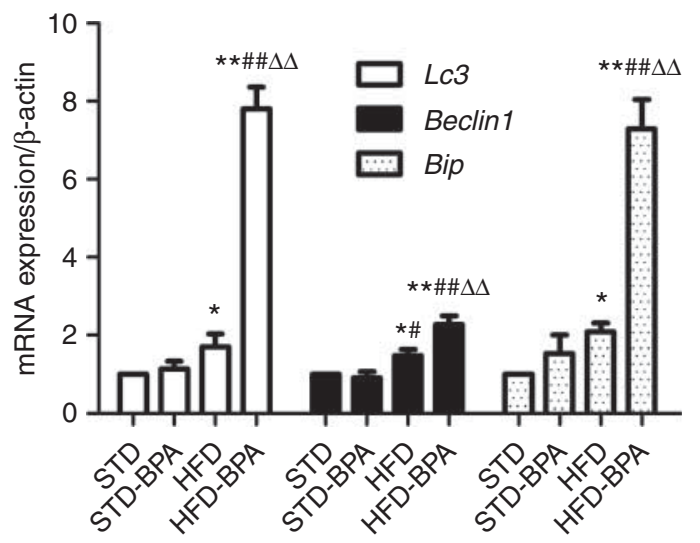

Figure 4

The mRNA expression in the pancreas of paternal rats ( $n=3$ per group). Expression of each gene was calculated with $\beta$-actin as the reference. Results are expressed as mean \pm S.E.M. ${ }^{*} P<0.05$ and ${ }^{*} P<0.01$ compared with STD; ${ }^{\#} P<0.05$ and ${ }^{\# \#} P<0.01$ compared with STD-BPA; $\Delta \Delta, P<0.01$ compared with HFD.

Published by Bioscientifica Ltd. 
insulin level was significantly increased in the BPA-treated groups compared with the untreated groups $(P<0.05)$, as well as in the STD-BPA group compared with the STD group $(P<0.01)$, but no significant difference was observed between HFD and HFD-BPA group (Fig. 2B). There was no significant difference in the levels of serum and liver TG (Fig. 2C and E) or TC (Fig. 2D and F) between the BPA-treated groups and the control groups. However, the levels of serum and liver total TG and TC in HFD-fed groups were higher than those of the STD-fed groups $(P<0.05$ and $P<0.01)$.

\section{GTT and HOMA-IR in paternal rats}

A significant increase in HOMA-IR and a significant decrease in ISI were both observed in HFD-treated and BPA-treated groups vs the control group $(P<0.01$; see
Fig. 2G and H). Furthermore, interaction effects between exposure duration and variety of diet, as well as between exposure duration and BPA treatment on HOMA-IR and ISI were observed (Fig. 2G and $\mathrm{H}$ ). To examine the effect of BPA treatment on glucose tolerance, we measured the blood glucose at different time points after the 30-week treatment (Fig. 2I and J). IPGTT results revealed that blood glucose and AUC were increased in HFD-treated and BPAtreated groups vs the control group $(P<0.01)$, see Fig. 2I and J. The blood glucose of the HFD-BPA group displayed a statistically significant increase compared with the HFD group at 15 and 30 min (Fig. 2I). Moreover, a significant interaction effect between BPA treatment and variety of diet $(P<0.05)$, as well as between BPA treatment and exposure duration $(P<0.05)$ on serum glucose were also observed. In addition, the AUC for the IPGTT showed
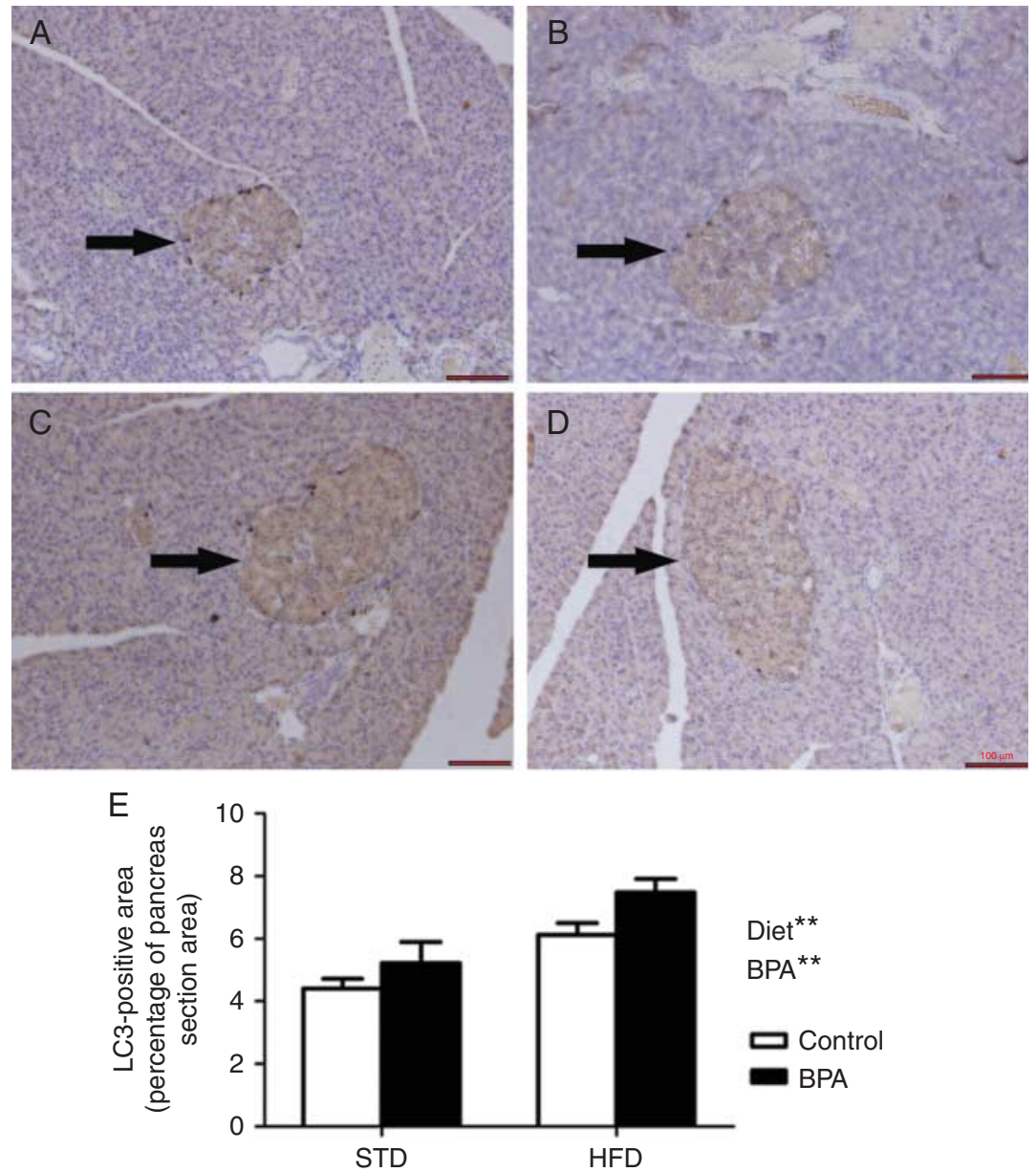

Figure 5

Immunohistochemistry staining results for the LC3 protein (brown, arrows) in the pancreatic islets of paternal rats. (A) STD, (B) STD-BPA, (C) HFD, and (D) HFD-BPA $(200 \times$ magnification, bars $=100 \mu \mathrm{m})$ represent immunostaining with LC3 in pancreatic tissue. (E) The LC3-positive/pancreas section area of pancreas in four groups. Data are shown as means \pm S.E.M. ${ }^{* * P} P<0.01$; diet** indicates the variety of diet and BPA** indicates BPA treatment. 
an interaction effect of BPA treatment and variety of diet on AUC in paternal rats treated for 30 weeks $(P<0.05)$. Taken together, these results indicated that BPA treatment induces insulin resistance, decreases insulin sensitivity, and induces glucose intolerance.

\section{Pancreatic $\beta$-cell mass in paternal rats}

Paternal rats in the STD-BPA, HFD, and HFD-BPA rats had mildly dilated islets (Fig. 3A, B, C and D). We found that consumption of the HFD markedly increased $\beta$-cell mass $(P<0.01)$, meanwhile significantly higher $\beta$-cell mass was observed in BPA-treated rats compared with the control groups $(P<0.01)$. There was an interaction between HFD and BPA treatment $(P<0.01$; see Fig. 3E).

\section{Quantitative real-time PCR of pancreas in paternal rats}

As shown in Fig. 4, the mRNA expression level of $L c 3$ and Bip in the HFD group was higher than that observed for the STD group $(P<0.05)$; moreover, mRNA expression levels of $L c 3$ and Bip' in the HFD-BPA group were significantly increased compared with the other three groups $(P<0.01)$. In addition, expression of Beclin1 was markedly increased in the HFD-fed groups compared with the STD-fed groups, and the levels of Beclin1 was significantly increased in the HFD-BPA group compared with the other three groups $(P<0.01)$.

A
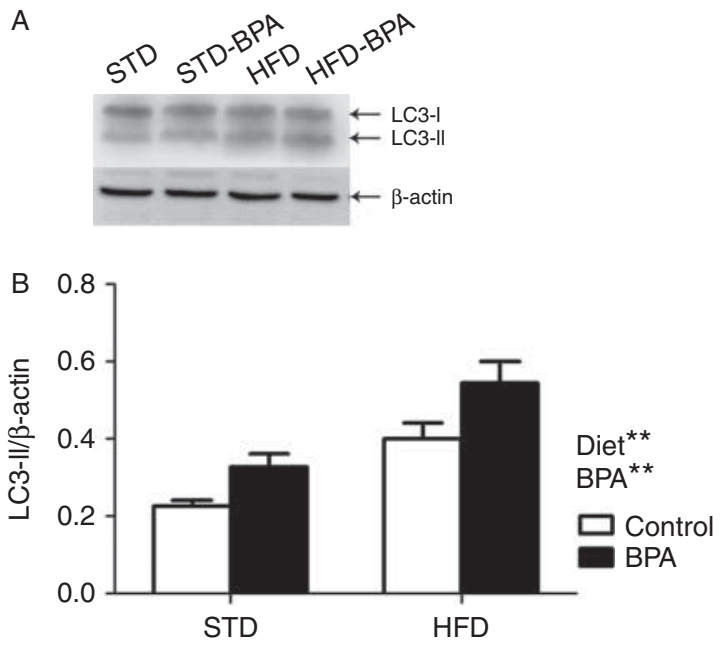

Figure 6

LC3-I and LC3-II protein expressions in the pancreas of paternal rats. (A) Western blotting results for LC3 protein. (B) Quantitative analysis of LC3-II band densities $(n=3)$. Protein expression data are presented as mean \pm s.E.M. ${ }^{*} * P<0.01$; Diet**indicates the variety of diet; BPA**indicates BPA treatment.

\section{Protein expression of LC3 in paternal pancreas and $\beta$-cells}

Total LC3-positive pancreas area/total pancreas section area was significantly increased in HFD-treated and BPA-treated groups vs the control group $(P<0.05$; see Fig. 5A, B, C, D and E). LC3-II protein expression in the pancreas of rats was upregulated in HFD-treated and BPA-treated groups vs the control group $(P<0.01$; Fig. $6 \mathrm{~A}$ and $\mathrm{B})$. In addition, immunofluorescence analysis confirmed that there was upregulated expression of LC3 protein in the pancreatic $\beta$-cells of animals in the HFD-treated and BPA-treated groups vs those in the control group (Fig. 7).

\section{Reproductive outcomes for offspring}

On PND 1, there was no difference in the litter size, average birth weight, or sex ratio among the four groups (Fig. 8A, B and $\mathrm{C}$ ). Paternal exposure to BPA did not result in a significant difference in body weight in male and female offspring before weaning (Fig. 8D and E). Overall, these results indicated that BPA exposure of paternal adult rats has no significant effect on litter size, average birth weight, sex ratio, and body weight before weaning of their offspring.

\section{Serum metabolite levels in 10-week-old offspring}

The results demonstrated that paternal exposure to BPA for 21 weeks did not alter serum metabolite levels in 10 -week-old male or female offspring. Furthermore, there was no difference in serum metabolite levels, including glucose, insulin, TG, and TC between male and female offspring within each treatment group $(P>0.05$; see Fig. 9A, B, C and D). Moreover, no significant difference was observed in HOMA-IR and ISI of the offspring in the four groups $(P>0.05)$ or between male and female offspring within each treatment group $(P>0.05)$ (see Fig. 9E and F).

\section{Discussion}

To our knowledge, there is no report about the effects of long-term and 'safe' doses of BPA treatment on glucose homeostasis, as well as of paternal BPA treatment on glucose and lipid metabolism of their offspring. In the present study, we have observed that long-term and environmental exposure level of BPA affect glucose homeostasis in adult male genitor rats fed with STD or HFD, and that HFD aggravated the adverse effect of BPA treatment. In addition, paternal BPA exposure has

Published by Bioscientifica Ltd. 


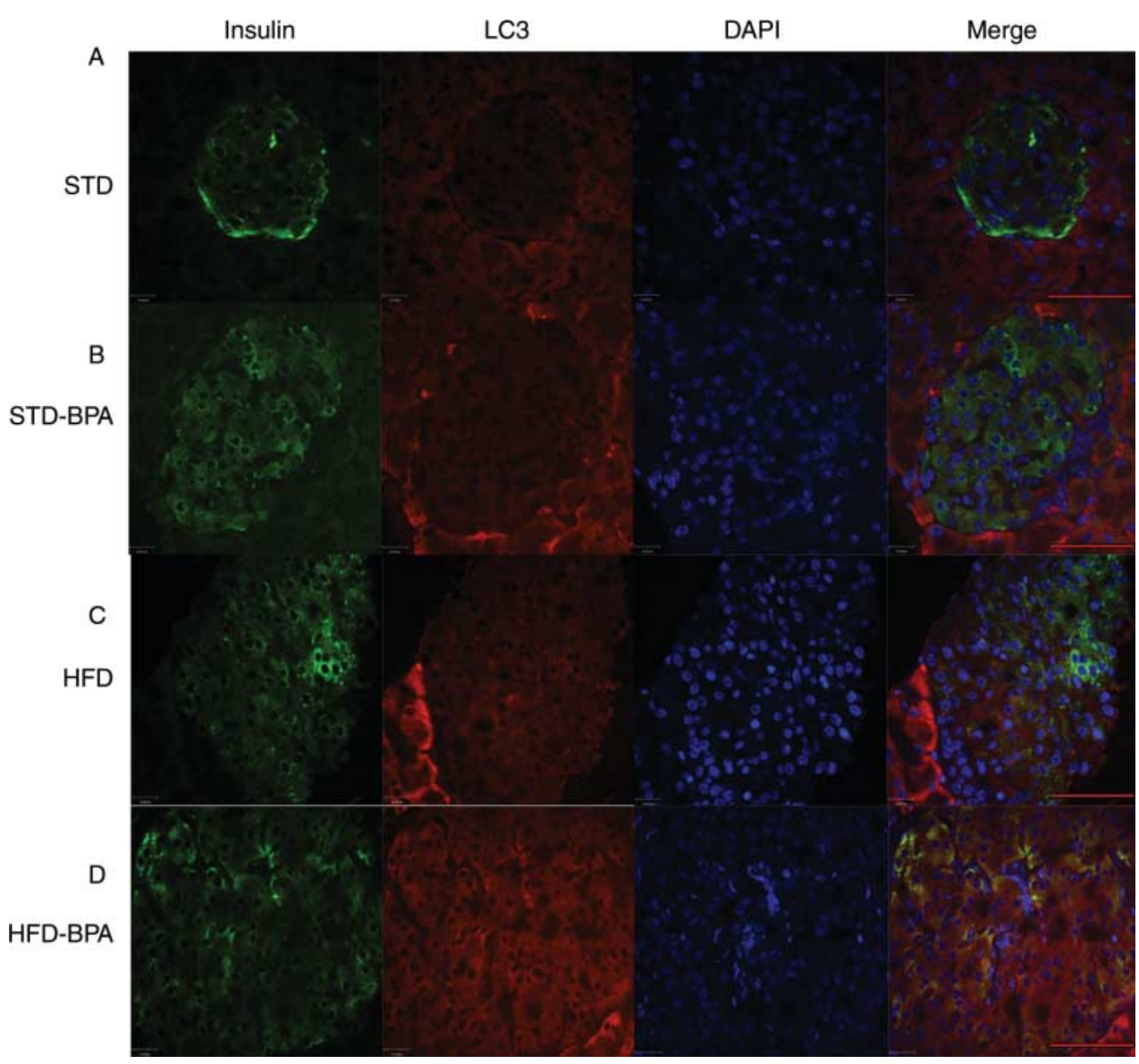

\section{Figure 7}

Representative confocal microscopy images showing the protein expression level of LC3 in pancreatic $\beta$-cells of paternal rats. The green areas represent $\beta$-cells and red represents LC3 protein expression. (A) STD,

no effects on glucose and lipid metabolism of their adult offspring.

Using self-reported diabetes as the outcome in studies has been demonstrated to underestimate the true prevalence of diabetes (Kehoe et al. 1994). This may lead to misclassification of T2DM and indicate no significant association between urine BPA and T2DM in several large
(B) STD-BPA, (C) HFD, and (D) HFD-BPA ( $400 \times$ magnification, bars $=50 \mu \mathrm{m})$ showing colocalization of the distribution of LC3 and $\beta$-cells in rat pancreas.

cross-sectional population-based studies. To limit the bias of misclassification, circulating levels of fasting glucose and insulin were used to study the association of BPA and insulin resistance. Recently, positive associations of BPA levels with insulin resistance have been observed in middleaged and elderly Chinese adults (Wang et al. 2012), as well as in adults in the USA (Beydoun et al. 2013).
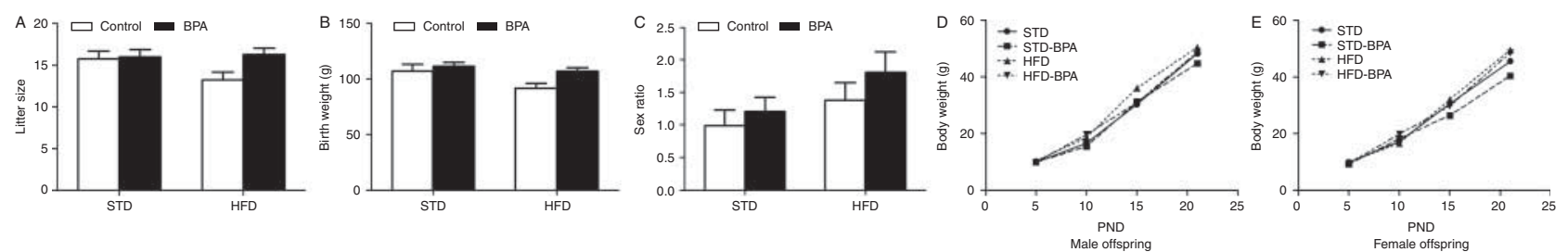

Figure 8

Reproductive outcomes for F1 pups ( $n=4$ litters/group). (A) The litter size of offspring on PND 1. (B) The average birth weight of offspring on PND 1. (C) Sex ratio (number of male pups/number of female pups) of live births in
F1 pups on PND 1. (D) Body-weight trajectories of F1 males on PND 5, 10, 15 , and 21. (E) Body-weight trajectories of F1 females on PND 5, 10, 15, and 21. Data are expressed as mean \pm S.E.M.

Published by Bioscientifica Ltd 

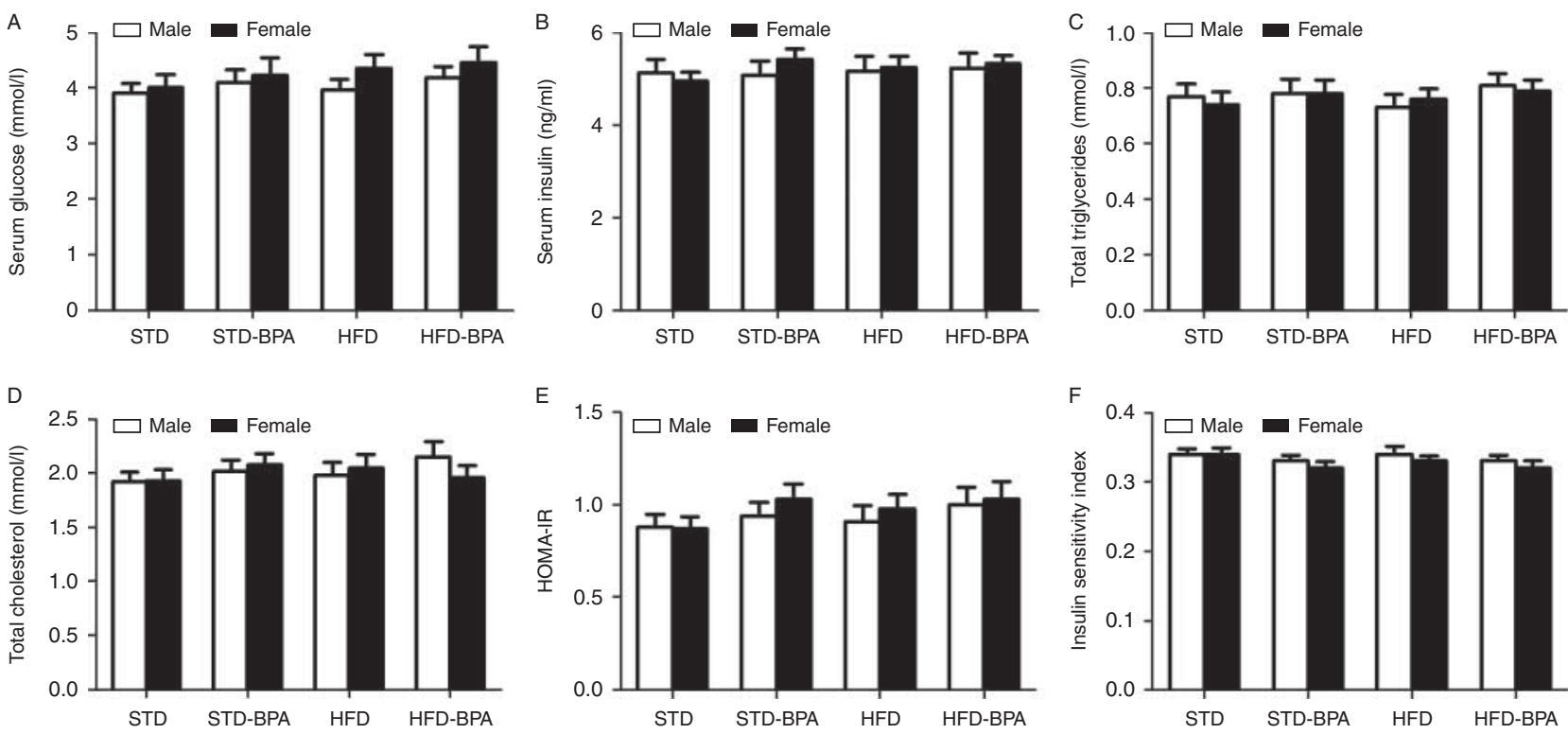

Figure 9

Serum metabolite levels in male and female offspring at the age of 10 weeks $(n=10)$. (A) Serum glucose, (B) serum insulin, (C) total triglycerides, (D) total cholesterol, (E) HOMA-IR, and (F) insulin sensitivity index. Data are expressed as mean \pm s.E.M.

Furthermore, a positive association of urinary BPA levels with pre-diabetes among non-diabetic adults in the USA has been reported by Sabanayagam et al. (2013). These findings add to the emerging evidence of the adverse effects of BPA on T2DM in humans. Recently, some in vivo studies have observed adverse effects of BPA, and BPA below the predicted 'safe dose' established by the U.S. EPA disrupted $\beta$-cell function and induced insulin resistance in male mice (Alonso-Magdalena et al. 2006, Marmugi et al. 2012). These results indicate that the 'safe' dose of BPA may not be safe. The development of insulin resistance precedes the occurrence of hyperglycemia and is sustained for a long time before diabetes (Kahn 2003), and insulin resistance induces decreased glucose intake in targeted tissues. In this study, glucose intolerance was observed in the HFD-treated and BPA-treated groups, this implies that the existence of insulin resistance and loaded glucose cannot be reduced rapidly by insulin in rats after 30 weeks of treatment. Elevated fasting serum glucose and HOMAIR and ISI were observed in BPA-treated rats after 35 weeks of treatment. These results further indicated that BPA may disrupt blood glucose homeostasis and damage pancreas function in STD- and HFD-fed rats. The increased insulin resistance and disrupted glucose homeostasis reported in the rodents of the study of Alonso-Magdalena et al. (2006) and our present study were also reported by Beydoun et al. (2013) in adults in the USA with higher BPA burden.
The hyperglycemia with hyperinsulinism in rats in the BPA-treated groups observed in our study had also been reported in the study of Alonso-Magdalena et al. (2006), and they predicted that this may be due to a direct effect on $\beta$ cells, or an indirect effect of insulin resistance or both. In a later study, they further demonstrated that BPA has a direct effect on the pancreas and therefore can cause hyperinsulinemia (Alonso-Magdalena et al. 2008). The Western diet model, with increased high-fat consumption, is an important risk factor for T2DM. Our data indicated that impaired glucose tolerance in the HFD-BPA group was more serious than that in the HFD group after 30 weeks of treatment. Furthermore, the blood glucose was significantly increased in the HFD-BPA group after 35 weeks of treatment. These data indicated that HFD consumption aggravated the occurrence of these adverse effects induced by the 'safe' dose of BPA.

In our study, no effects of BPA was observed on body weight or body fat percentage, which is in agreement with results of a previous study in which 5-week-old fructose-fed Fischer 344 female rats were treated with $54.3 \mu \mathrm{g} / \mathrm{kg}$ per day (mean) BPA for 10 weeks via drinking water (Ronn et al. 2013). Alteration of body fat percentage led to elevated levels of TG and TC in BPA-exposed rats (Wei et al. 2011). No BPA-treatment-related alterations of TG and TC in serum or liver were observed in our study, this is consistent with absence of any alteration of body fat percentage. 
In this study, we also examined the hypothesis that $\beta$-cell dysfunction induced by BPA treatment is associated with upregulated ER stress and autophagy in pancreas. Increased $\beta$-cell mass (Ribeiro et al. 2012) and autophagy (Fujitani et al. 2009), which were considered to protect $\beta$-cells, had been reported in mice fed with HFD. In our study, both HFD and BPA treatment increased pancreatic $\beta$-cell mass. The autophagy marker Lc3/Atg8 and autophagy-associated protein Beclin1 exhibited significant increases in $\beta$-cells and/or pancreas of rats in the HFD and HFD-BPA groups. This is consistent with the increased $\beta$-cell mass and Bip expression. All these results indicate that autophagy is activated as a defensive response for survival during ER stress (Ogata et al. 2006, Ding et al. 2007). Upregulated autophagy in the islets of rats may be used to deal with accumulation of misfolded and aggravated proteins and remove the abnormal unnecessary cellular components in $\beta$-cells. Increased protein expression of LC3 in the pancreas indicated that autophagy is essential for maintaining the function of pancreas, and that pancreatic $\beta$-cells may be protected by upregulated autophagy under insulin-resistant states caused by HFD and BPA treatment. In brief, BPA may exert an influence on $\beta$-cell dysfunction with ER stress and enhanced autophagy. The field of ER stress and enhanced autophagy is a promising one for $\beta$-cell dysfunction treatment, and the exact mechanism need to be further studied.

Some studies revealed that fathers have played a vital role in obesity, which led to metabolic alteration in their offspring (Tarquini et al. 1999, Power et al. 2003). Ng et al. (2010) also demonstrated that HFD could induce nongenetic intergenerational transmission of glucose metabolic disorder from father to offspring. In our study, a 'safe' dose of BPA treatment caused paternal insulin resistance before mating, but the birth weight of offspring was not altered. The body weight of offspring in the HFD group had a lower tendency than the other groups, which may have been caused by limited litter numbers. Knight et al. (2006) reported that birth weight of offspring is not associated with paternal insulin resistance in a community-based study of UK, which is in agreement with our results. In addition, paternal BPA treatment has no effect on serum metabolites in adult offspring of either sex. These results indicate that BPA-induced glucose metabolic disorder in paternal rats could not disrupt blood glucose and lipid homeostasis in offspring by intergenerational transmission, but this is distinct from results of another study, which reported that reporting maternal BPA $(50 \mu \mathrm{g} / \mathrm{kg}$ per day) exposure increased bodyweight, elevated insulin, and impaired glucose tolerance in adult offspring (Wei et al. 2011). In addition, no alterations were observed of sex ratio and litter size of F1 pups at birth in our study. These findings are consistent with those of a prior study on pregnant Sprague-Dawley rats exposed to BPA (70 $\mu \mathrm{g} / \mathrm{kg}$ per day) during gestational period (Somm et al. 2009). It would be interesting to clarify the different mechanism between paternal and maternal BPA exposure on offspring in further studies.

In our study, the treatment method not only imitates the diet route of BPA exposure in humans but also reduces the anguish of gavages. We also analyzed the interaction effects between BPA and HFD. One caveat of our study could be that we did not further observe the glucose and lipid metabolism of STD-fed offspring when they were aged.

In conclusion, we first reported that long-term and predicted 'safe' dose of BPA treatment disrupted blood glucose homeostasis in adult male rats, and that HFD aggravated these adverse effects. In addition, increased autophagy in pancreas and $\beta$-cell was involved in BPAinduced adverse effects. Moreover, paternal BPA treatment did not lead to metabolic disorder in offspring through intergenerational transmission. On the whole, BPA is a risk factor for T2DM and high fat consumption may aggravate glucose metabolic disorder.

\section{Declaration of interest}

The authors declare that there is no conflict of interest that could be perceived as prejudicing the impartiality of the research reported.

\section{Funding}

This work was supported by the National Basic Research Program of China (973 Program) project number: 2012CB722401, the National Natural Science Foundation of China (grant numbers 81030051, 81172674, and 81273060), and the Specialized Research Fund for the Doctoral Program of Higher Education of China (20110142110022).

\section{References}

Alonso-Magdalena P, Morimoto S, Ripoll C, Fuentes E \& Nadal A 2006 The estrogenic effect of bisphenol A disrupts pancreatic $\beta$-cell function in vivo and induces insulin resistance. Environmental Health Perspectives 114 106-112. (doi:10.1289/ehp.8451)

Alonso-Magdalena P, Ropero AB, Carrera MP, Cederroth CR, Baquie M, Gauthier BR, Nef S, Stefani E \& Nadal A 2008 Pancreatic insulin content regulation by the estrogen receptor ER $\alpha$. PLOS ONE 3 e2069. (doi:10.1371/journal.pone.0002069)

Alonso-Magdalena P, Vieira E, Soriano S, Menes L, Burks D, Quesada I \& Nadal A 2010 Bisphenol A exposure during pregnancy disrupts glucose homeostasis in mothers and adult male offspring. 
Environmental Health Perspectives 118 1243-1250. (doi:10.1289/ehp. 1001993)

Bachar-Wikstrom E, Wikstrom JD, Ariav Y, Tirosh B, Kaiser N, Cerasi E \& Leibowitz G 2013 Stimulation of autophagy improves endoplasmic reticulum stress-induced diabetes. Diabetes 62 1227-1237. (doi:10.2337/db12-1474)

Beydoun HA, Khanal S, Zonderman AB \& Beydoun MA 2013 Sex differences in the association of urinary bisphenol-A concentration with selected indices of glucose homeostasis among U.S. adults. Annals of Epidemiology 24 90-97. (doi:10.1016/j.annepidem.2013.07.014)

Boslem E, Weir JM, Macintosh G, Sue N, Cantley J, Meikle PJ \& Biden TJ 2013 Alteration of endoplasmic reticulum lipid rafts contributes to lipotoxicity in pancreatic $\beta$-cells. Journal of Biological Chemistry $\mathbf{2 8 8}$ 26569-26582. (doi:10.1074/jbc.M113.489310)

Bukau B, Weissman J \& Horwich A 2006 Molecular chaperones and protein quality control. Cell 125 443-451. (doi:10.1016/j.cell.2006.04.014)

Ding WX, Ni HM, Gao W, Hou YF, Melan MA, Chen X, Stolz DB, Shao ZM \& Yin XM 2007 Differential effects of endoplasmic reticulum stressinduced autophagy on cell survival. Journal of Biological Chemistry $\mathbf{2 8 2}$ 4702-4710. (doi:10.1074/jbc.M609267200)

Fan Y, Ding S, Ye X, Manyande A, He D, Zhao N, Yang H, Jin X, Liu J, Tian C et al. 2013 Does preconception paternal exposure to a physiologically relevant level of bisphenol A alter spatial memory in an adult rat? Hormones and Behavior 64 598-604. (doi:10.1016/ j.yhbeh.2013.08.014)

Fu Z, Gilbert ER, Pfeiffer L, Zhang Y, Fu Y \& Liu D 2012 Genistein ameliorates hyperglycemia in a mouse model of nongenetic type 2 diabetes. Applied Physiology, Nutrition, and Metabolism 37 480-488. (doi:10.1139/h2012-005)

Fujitani Y, Kawamori R \& Watada H 2009 The role of autophagy in pancreatic $\beta$-cell and diabetes. Autophagy 5 280-282. (doi:10.4161/auto. 5.2.7656)

Garofano A, Czernichow P \& Breant B 1998 ß-Cell mass and proliferation following late fetal and early postnatal malnutrition in the rat. Diabetologia 41 1114-1120. (doi:10.1007/s001250051038)

Guariguata L, Whiting D, Weil C \& Unwin N 2011 The International Diabetes Federation diabetes atlas methodology for estimating global and national prevalence of diabetes in adults. Diabetes Research and Clinical Practice 94 322-332. (doi:10.1016/j.diabres.2011. 10.040)

Hu FB 2011 Globalization of diabetes: the role of diet, lifestyle, and genes. Diabetes Care 34 1249-1257. (doi:10.2337/dc11-0442)

Jung HS, Chung KW, Won Kim J, Kim J, Komatsu M, Tanaka K, Nguyen YH, Kang TM, Yoon KH, Kim JW et al. 2008 Loss of autophagy diminishes pancreatic $\beta$ cell mass and function with resultant hyperglycemia. Cell Metabolism 8 318-324. (doi:10.1016/j.cmet.2008. 08.013)

Kahn SE 2003 The relative contributions of insulin resistance and $\beta$-cell dysfunction to the pathophysiology of type 2 diabetes. Diabetologia 46 3-19. (doi:10.1007/s00125-003-1190-9)

Kehoe R, Wu SY, Leske MC \& Chylack LT Jr 1994 Comparing self-reported and physician-reported medical history. American Journal of Epidemiology 139 813-818.

Kim K \& Park H 2013 Association between urinary concentrations of bisphenol A and type 2 diabetes in Korean adults: a population-based cross-sectional study. International Journal of Hygiene and Environmental Health 216 467-471. (doi:10.1016/j.ijheh.2012.07.007)

Knight B, Shields BM, Hill A, Powell RJ, Round A, Hamilton W \& Hattersley AT 2006 Offspring birthweight is not associated with paternal insulin resistance. Diabetologia 49 2675-2678. (doi:10.1007/ s00125-006-0417-y)

Kuma A, Hatano M, Matsui M, Yamamoto A, Nakaya H, Yoshimori T, Ohsumi Y, Tokuhisa T \& Mizushima N 2004 The role of autophagy during the early neonatal starvation period. Nature 432 1032-1036. (doi:10.1038/nature03029)
Lang IA, Galloway TS, Scarlett A, Henley WE, Depledge M, Wallace RB \& Melzer D 2008 Association of urinary bisphenol A concentration with medical disorders and laboratory abnormalities in adults. Journal of the American Medical Association 300 1303-1310. (doi:10.1001/jama.300. 11.1303)

Lee AH, Iwakoshi NN \& Glimcher LH 2003 XBP-1 regulates a subset of endoplasmic reticulum resident chaperone genes in the unfolded protein response. Molecular and Cellular Biology 23 7448-7459. (doi:10.1128/MCB.23.21.7448-7459.2003)

Levine B \& Klionsky DJ 2004 Development by self-digestion: molecular mechanisms and biological functions of autophagy. Developmental Cell 6 463-477. (doi:10.1016/S1534-5807(04)00099-1)

Loison C, Mendy F, Serougne C \& Lutton C 2002 Dietary myristic acid modifies the HDL-cholesterol concentration and liver scavenger receptor BI expression in the hamster. British Journal of Nutrition $\mathbf{8 7}$ 199-210. (doi:10.1079/BJN2002521)

Marmugi A, Ducheix S, Lasserre F, Polizzi A, Paris A, Priymenko N, Bertrand-Michel J, Pineau T, Guillou H, Martin PG et al. 2012 Low doses of bisphenol A induce gene expression related to lipid synthesis and trigger triglyceride accumulation in adult mouse liver. Hepatology $\mathbf{5 5}$ 395-407. (doi:10.1002/hep.24685)

Matthews DR, Hosker JP, Rudenski AS, Naylor BA, Treacher DF \& Turner RC 1985 Homeostasis model assessment: insulin resistance and $\beta$-cell function from fasting plasma glucose and insulin concentrations in man. Diabetologia 28 412-419. (doi:10.1007/BF00280883)

Melzer D, Rice NE, Lewis C, Henley WE \& Galloway TS 2010 Association of urinary bisphenol A concentration with heart disease: evidence from NHANES 2003/06. PLOS ONE 5 e8673. (doi:10.1371/journal.pone. 0008673)

Miani M, Barthson J, Colli ML, Brozzi F, Cnop M \& Eizirik DL 2013 Endoplasmic reticulum stress sensitizes pancreatic $\beta$ cells to interleukin-1 $\beta$-induced apoptosis via Bim/A1 imbalance. Cell Death and Disease 4 e701. (doi:10.1038/cddis.2013.236)

Ng SF, Lin RC, Laybutt DR, Barres R, Owens JA \& Morris MJ 2010 Chronic high-fat diet in fathers programs $\beta$-cell dysfunction in female rat offspring. Nature 467 963-966. (doi:10.1038/nature09491)

Ning G, Bi Y, Wang T, Xu M, Xu Y, Huang Y, Li M, Li X, Wang W, Chen Y et al. 2011 Relationship of urinary bisphenol A concentration to risk for prevalent type 2 diabetes in Chinese adults: a cross-sectional analysis. Annals of Internal Medicine 155 368-374. (doi:10.7326/0003-4819-1556-201109200-00005)

Ogata M, Hino S, Saito A, Morikawa K, Kondo S, Kanemoto S, Murakami T, Taniguchi M, Tanii I, Yoshinaga Ket al. 2006 Autophagy is activated for cell survival after endoplasmic reticulum stress. Molecular and Cellular Biology 26 9220-9231. (doi:10.1128/MCB.01453-06)

Perreault L, McCurdy C, Kerege AA, Houck J, Faerch K \& Bergman BC 2013 Bisphenol a impairs hepatic glucose sensing in C57BL/6 male mice. PLOS ONE 8 e69991. (doi:10.1371/journal.pone.0069991)

Power C, Li L, Manor O \& Davey Smith G 2003 Combination of low birth weight and high adult body mass index: at what age is it established and what are its determinants? Journal of Epidemiology and Community Health 57 969-973. (doi:10.1136/jech.57.12.969)

Quan W, Lim YM \& Lee MS 2012 Role of autophagy in diabetes and endoplasmic reticulum stress of pancreatic $\beta$-cells. Experimental and Molecular Medicine 44 81-88. (doi:10.3858/emm.2012.44.2.030)

Ribeiro RA, Santos-Silva JC, Vettorazzi JF, Cotrim BB, Mobiolli DD, Boschero AC \& Carneiro EM 2012 Taurine supplementation prevents morpho-physiological alterations in high-fat diet mice pancreatic $\beta$-cells. Amino Acids 43 1791-1801. (doi:10.1007/s00726012-1263-5)

Ronn M, Kullberg J, Karlsson H, Berglund J, Malmberg F, Orberg J, Lind L, Ahlstrom H \& Lind PM 2013 Bisphenol A exposure increases liver fat in juvenile fructose-fed Fischer 344 rats. Toxicology 303C 125-132. (doi:10.1016/j.tox.2012.09.013)

Sabanayagam C, Teppala S \& Shankar A 2013 Relationship between urinary bisphenol A levels and prediabetes among subjects free of 
diabetes. Acta Diabetologica 50 625-631. (doi:10.1007/s00592-0130472-z)

Shankar A \& Teppala S 2011 Relationship between urinary bisphenol A levels and diabetes mellitus. Journal of Clinical Endocrinology and Metabolism 96 3822-3826. (doi:10.1210/jc.2011-1682)

Simental-Mendia LE, Castaneda-Chacon A, Rodriguez-Moran M \& GuerreroRomero F 2012 Birth-weight, insulin levels, and HOMA-IR in newborns at term. BMC Pediatrics 12 94. (doi:10.1186/1471-2431-12-94)

Somm E, Schwitzgebel VM, Toulotte A, Cederroth CR, Combescure C, Nef S, Aubert ML \& Huppi PS 2009 Perinatal exposure to bisphenol A alters early adipogenesis in the rat. Environmental Health Perspectives 117 1549-1555. (doi:10.1289/ehp.11342)

Tarquini B, Tarquini R, Perfetto F, Cornelissen G \& Halberg F 1999 Genetic and environmental influences on human cord blood leptin concentration. Pediatrics 103 998-1006. (doi:10.1542/peds. 103.5.998)

Tian C, Ye X, Zhang R, Long J, Ren W, Ding S, Liao D, Jin X, Wu H, Xu S et al. 2013 Green tea polyphenols reduced fat deposits in high fat-fed rats via erk1/2-PPAR $\gamma$-adiponectin pathway. PLOS ONE 8 e53796. (doi:10.1371/journal.pone.0053796)
Vandenberg LN, Hauser R, Marcus M, Olea N \& Welshons WV 2007 Human exposure to bisphenol A (BPA). Reproductive Toxicology 24 139-177. (doi:10.1016/j.reprotox.2007.07.010)

Wang T, Li M, Chen B, Xu M, Xu Y, Huang Y, Lu J, Chen Y, Wang W, Li X et al. 2012 Urinary bisphenol A (BPA) concentration associates with obesity and insulin resistance. Journal of Clinical Endocrinology and Metabolism 97 E223-E227. (doi:10.1210/jc.2011-1989)

Wang M, Gao X, Zhao W, Jiang S, Huang F, Kou J, Liu B \& Liu K 2013 Opposite effects of genistein on regulation of insulin-mediated glucose homeostasis in adipose tissue. British Journal of Pharmacology $\mathbf{1 7 0}$ 328-340. (doi:10.1111/bph.12276)

Wei J, Lin Y, Li Y, Ying C, Chen J, Song L, Zhou Z, Lv Z, Xia W, Chen $X$ et al. 2011 Perinatal exposure to bisphenol A at reference dose predisposes offspring to metabolic syndrome in adult rats on a high-fat diet. Endocrinology 152 3049-3061. (doi:10.1210/en.2011-0045)

Ying CJ, Xu JW, Ikeda K, Takahashi K, Nara Y \& Yamori Y 2003 Tea polyphenols regulate nicotinamide adenine dinucleotide phosphate oxidase subunit expression and ameliorate angiotensin II-induced hyperpermeability in endothelial cells. Hypertension Research 26 823-828. (doi:10.1291/hypres.26.823)

Received in final form 16 January 2014

Accepted 5 February 2014

Accepted Preprint published online 5 February 2014
(C) 2014 Society for Endocrinology Printed in Great Britain
Published by Bioscientifica Ltd. 